\title{
Specialized Regional Conferences Support the Professional Development Needs of Subject Librarians: A 5-Year Analysis of the Great Lakes Science Boot Camps for Librarians
}

\author{
Bethany McGowan, Jennifer Hart, and Karen Hum
}

Conference attendance can play an important role in supporting the professional development of subject librarians by offering opportunities that allow librarians to learn about new services, strategies, and technologies while growing and maintaining professional networks. However, barriers such as accessibility challenges, budgetary and resource restrictions, difficulty measuring learning gains, and difficulty measuring the value of professional development when applied to the job can restrict opportunities for many librarians. Specialized regional conferences have the potential to reduce many of these barriers. How can librarians, library administrators, and conference organizers quantify the value of regional conference attendance as an accessible means for fostering librarian professional development? This paper examines five years of assessment data and participant feedback from attendees of a specialized regional conference for STEM librarians and measures participant learning and participant motivation for conference attendance. We propose specialized regional conferences, such as the Great Lakes Science Boot Camp for Librarians, as accessible and affordable continuing education opportunities that support the professional development of subject librarians.

\section{Introduction}

Specialized librarianship requires subject knowledge and skill with specific tools and technologies. Subject librarians seeking professional development need continuing education opportunities that address their unique, subject-specific needs. Regional conferences with a focus on a specialized librarianship theme offer valuable professional development opportunities. However, justifying conference attendance as a professional development opportunity and measuring the impact of conference attendance once librarians have returned to their home institutions is difficult and can be a barrier for librarians and library administrators. Other

Bethany McGowan is Assistant Professor of Library Science and Health Sciences Information Specialist in the Purdue University Libraries and School of Information Studies; email: bmcgowa@purdue.edu. Jenny Hart is Librarian for Computer Science, Mathematics, Physics and Statistics at the University of Chicago; email: hartj@uchicago. edu. Karen Hum is Director of Assessment for the Purdue University Libraries and School of Information Studies in West Lafayette, Indiana; email: humk@purdue.edu. (C2021 Bethany McGowan, Jennifer Hart, and Karen Hum, Attribution-NonCommercial (https://creativecommons.org/licenses/by-nc/4.0/) CC BY-NC. 
barriers to conference attendance include budget and resource restrictions and accessibility challenges. These issues are especially crippling for librarians in small, rural, or low-resource libraries. We hypothesize that specialized regional conferences, such as the Great Lakes Science Boot Camp for Librarians and Library School Students (GLSBC), help to reduce many of the aforementioned barriers. We propose that the GLSBC's regional focus improves accessibility and affordability; that its focus on STEM-used here to include disciplines related to science, technology, engineering, agriculture, mathematics, and medicine-librarian training meets the unique professional development needs of a specialized target audience; and that the camp's use and assessment of clear and measurable learning objectives make it possible to measure the impact of conference attendance. To test our hypothesis, this paper examines five years (2015-2019) of GLSBC assessment data and participant feedback, measuring how well the camps met their learning objectives and measuring attendee motivation.

\section{Background}

The Great Lakes Science Boot Camp for Librarians and Library School Students was launched at Wayne State University in 2015 with funding from the National Network of Libraries of Medicine, Greater Midwest Region. GLSBC provides a continuing education experience that focuses on achieving three learning objectives: 1) Participants will gain detailed knowledge of the current state of scientific and biomedical research, including new terminologies and methodologies; 2) Participants will develop strategies to enhance their support of scientific research at their home institutions; and 3) Participants will identify opportunities for librarian engagement. After its pilot, GLSBC became an annual event and was hosted by the University of Notre Dame in 2016, by Michigan State University in 2017, by Purdue University in 2018, and by the University of Chicago in 2019. Survey responses from the 2015-2019 camps are included in this study.

GLSBC models the New England Science Boot Camp for Librarians, which was a response to the evolving professional development needs of science librarians. The UMass 5 Group, a committee of science librarians from the five campuses of the University of Massachusetts, asked researchers at their institutions to lead librarian education sessions in one-day and multiple-day events. The Science Boot Camp for Librarians, later called the New England Science Boot Camp for Librarians, emerged as an annual event. ${ }^{1}$ Several similar boot camp-style events have since emerged, including STEM Librarians South, South East Science Bootcamp, Science Boot Camp West, and True North Science Boot Camp.

In addition to supporting the professional development needs of STEM librarians, specialized regional conferences help address many of the barriers presented by national conferences. Several attributes make GLSBC affordable, with registration costs of about $\$ 250$ that include meals and lodging. There are no speaker fees or speaker travel costs. Instead, the camp relies on STEM faculty and researchers from the host institution to serve as speakers and lecturers. Also, the camp is independent and does not require a paid membership or affiliation with a professional organization or association. Each year, an academic institution in the Great Lakes region volunteers to host and support the camp, often with supplemental grant funding and sponsorships. The states representing the Great Lakes region remain undefined for the purposes of the GLSBC, but camps have been held in Michigan, Indiana, and Illinois. Though GLSBC registration is open to anyone, the majority of its attendees are STEM librarians in the Greater Midwest Region, and most attendees drive to the conference. 
GLSBC operates as a 2.5-day event, with an optional additional half day for immersive learning experiences and instructional workshops. Normally, the camp begins on a Wednesday morning or afternoon and ends by Friday afternoon. Attendees only need to spend 3 days away from the office to participate in all camp activities. For a sample camp schedule, the 2018 GLSBC schedule is available in an open institutional repository. ${ }^{2}$

\section{Literature Review}

\section{Specialized Regional Conferences Offer Unique Professional Development Opportunities for Subject Librarians}

Regional conferences with a specialized focus can offer unique librarian professional development opportunities. The work of many librarians requires subject knowledge and skills with specific technologies and tools. To do their job effectively and reach their constituencies, librarians often need professional development that addresses unique, subject-specific needs. Conferences with a general librarianship focus often do not offer such specific content. ${ }^{3}$ Those that focus on subject-specific knowledge can, however, be valuable. ${ }^{4}$ Many librarians come to STEM librarianship in particular, with little to no background in the discipline or disciplines they will be serving. Those who do have a background in an area of science often take on liaison responsibilities for other science subjects in which they lack familiarity. ${ }^{5}$ Many library conferences such as the ALA, ACRL, SLA, and MLA conferences focus on librarianship and do not usually offer programming from the perspective of disciplinary practitioners.

To gain an understanding of disciplinary practices, some librarians attend disciplinespecific conferences. These conferences bring together researchers and other practitioners in a specific field and offer valuable content for subject librarians that library conferences often lack. ${ }^{6}$ Programming is dominated by presentations by faculty, researchers, and students in a field. This allows librarians to hear directly from people who work in the disciplines they support-how they work, trends in their field, what skills they need, and the technologies they use - which offers valuable insights into how librarians can better address the information needs of their own institution's faculty and allows librarians to provide more effective outreach. ${ }^{7}$ Discipline-specific conferences, however, are also often national. And they usually only cover one discipline, while many subject librarians handle multiple subject areas. Attending multiple disciplinary conferences can be cost-prohibitive and is not always a viable option. Observing the behaviors and habits of disciplinary researchers can help subject librarians develop competencies that make it easier to connect with faculty and instruct students. For example, a conference that focuses on STEM-specific disciplinary research would support STEM librarian professional development. ${ }^{8}$

In her 2014 article on the professional development of library and information professionals, Samantha Schmehl Hines defines continuing education as:

\footnotetext{
"formal lectures, courses, seminars, webinars, and any other type of educational program designed to educate an individual and give him or her further skills or knowledge to be applied in his or her line of work. These programs are intended to educate persons on new advancements, or to build on a person's expertise in a given field." $" 9$
}

Hines defines professional development as: 
"(the) process of improving and increasing capabilities of staff through access to education and training opportunities in the workplace, through outside organizations or through watching others perform the job. Professional development helps build and maintain morale of staff members and is thought to attract higher quality staff to an organization." 10

These definitions seemingly reinforce the concept of conference attendance as a continuing education opportunity that supports librarian professional development, and the findings of several studies suggest that conference attendance supports professional development. ${ }^{11}$ However, Hines questions this notion, noting several barriers.

\section{Barriers to Conference Attendance}

Barriers to conference attendance as a professional development opportunity for librarians include inaccessibility, unaffordability, and resource restrictions. ${ }^{12}$ Academic librarians and library administrators, faced with shrinking travel allowances, may find it difficult to justify the costs associated with conference attendance. Librarians also are often asked to front travel costs and then be reimbursed, sometimes months later. Librarians serving small and rural institutions are particularly disadvantaged by these barriers, due to the impact of such factors as increasingly tight budgets, stagnant salaries, small staff, and lack of access to current technologies, as expounded on by Davis Kendrick, Tritt, and Leaver. ${ }^{13}$ National conferences can be expensive, as professional organizations tend to hold these events in large, metropolitan cities that can accommodate them, resulting in costly food, lodging, and transportation options. And national conferences often require membership to professional organizations or substantial registration costs, factors that further reduce their accessibility and affordability.

Other barriers that make it challenging to justify the costs of conference attendance are related to the measurable impact of conference attendees' learning. It can be difficult to assess learning from conference attendance. And it can be difficult to measure the impact of conference attendance on the employee and potential beneficiaries, such as patrons, students, and researchers. Hines lists unconferences and virtual learning opportunities as alternatives to traditional conferences. ${ }^{14}$ We argue that specialized regional conferences also address the barriers posed by both Hines and Kendrick et al. A study of North American library workers found that, for 31 percent of respondents, the most recent conference attended was a state or provincial one. ${ }^{15}$ Though not as popular as national conferences, regional conferences offer several advantages for attendees.

\section{Regional Conferences Improve Conference Accessibility}

Regional conferences can be more accessible and less expensive than national conferences, as they are frequently hosted in smaller, cheaper venues. Travel options become cheaper, more robust, and more flexible when the possibility of traveling by car, train, or bus becomes available. And regional conferences are often shorter than national conferences, typically ranging between two and three days. This reduction in time away from the office could make attendance easier for librarians working in a library with a small staff. ${ }^{16}$

Because of their smaller size, regional conferences can offer a more intimate environment for networking and knowledge sharing among attendees. This can help foster a less intimidating and less overwhelming experience for participants and could prove an ideal experience 
for new professionals. Regional conferences offer a chance for librarians to interact with others with whom they may share geographic affiliations, which can support collection development and resource sharing, as many libraries are part of state and regional consortiums that include shared borrowing agreements and catalogs. Attending conferences and understanding the research and program strengths at other universities is valuable for librarians who could later direct patrons to these resources. ${ }^{17}$ Relatedly, regional conferences often include programming and tours related to local institutes, laboratories, special collections, and museums. Familiarizing librarians with these establishments can help them understand local research and resources available in their region. Networking with colleagues at regional conferences can foster connections for projects among librarians, including working groups, committees within consortiums, and research collaborations. GLSBC provides a regional setting for librarians to learn about the practices and research of disciplinary faculty from various disciplines.

\section{Learner-Centered Instruction Improves the Measurability of Learning Gains}

Hines suggests that the lack of a continuing education requirement for librarians makes it difficult to measure the quality of professional development and to assess learning gains. It also makes it difficult to measure the value of professional development when applied to the job..$^{18}$ Bilodeau and Carson reinforce this finding in their 2015 study, concluding that professional development among librarians is "self-directed, informal, highly dependent on social interaction with peers, and embedded in practice." ${ }^{\prime 19}$ To address these concerns, GLSBC has established clear and measurable learning objectives, an essential component of learnercentered education. ${ }^{20}$ To further its value, the GLSBC is annually registered as a formalized continuing education opportunity with the Medical Librarian Association.

Academic librarian Amanda Nichols Hess recommends that conference organizers use social learning theory, along with recommendations from the ACRL Framework for Information Literacy, to develop professional development opportunities that transform librarian instruction. ${ }^{21}$ Social learning theory proposes that new behaviors can be learned by observing and imitating others. ${ }^{22}$ GLSBC organizers rely on librarian-led talks, disciplinary faculty talks, and opportunities for casual networking among attendees to foster social learning. By networking with peer librarians and learning from librarian and STEM faculty talks, attendees can share successes and failures, brainstorm ideas about how to form partnerships with research teams on their campuses, and develop strategies to enhance their support of scientific research at their home institutions. ${ }^{23}$

To further foster learning, GLSBC focuses on learner-centered instruction pedagogies, encouraging attendees to be active participants in their learning. Camp activities include lectures and discussions with science researchers, facility and laboratory tours, field trips, librarian-led lightning talks, and casual networking events. Each day of the conference focuses on one or two STEM themes that provide an overview of emerging trends, research methodologies, and in-depth descriptions of current research projects. Learning directly from and interacting with STEM researchers exposes librarians to the current state of scientific and biomedical research, and allows librarians to experience how science faculty approach research.

\section{Study Objective}

We propose that specialized regional conferences, especially conferences that use learner-centered instruction, offer accessible and affordable continuing education opportunities for subject librar- 
ians. Our research question is as follows: How can organizers of specialized regional conferences help librarians and library administrators quantify the value of specialized regional conference attendance as an accessible means of fostering librarian professional development?

\section{Methods}

Approval for this study was granted by the Purdue University Institutional Review Board; study \#1805020609: Value Perceptions of the Great Lakes Science Boot Camp for Librarians Among Participants. The study was initially approved in May 2018 to survey participants at the 2018 GLSBC, hosted by Purdue University Libraries. The approval was modified in October 2019 to include assessment data shared by organizers of the previous and later boot camps.

A mixed-methods survey was used across all five years, collecting a combination of qualitative and quantitative data. Qualtrics survey software was used to design, collect, and store survey responses for all five years. The survey design and distribution for 2015, 2016, and 2017 boot camps were similar. A mixed-methods survey was distributed, via email, after participants left the conference. The survey was modified in 2018, adding questions that measured attendee demographics, professional organization membership, and previous boot camp attendance. The survey distribution approach also changed and the survey was distributed in paper form, as the final conference activity. These paper surveys were transcribed and stored in Qualtrics. The updated survey and the in-person distribution approach were also used for the 2019 camp. Examples of the original survey, used from 2015 to 2017, and the modified survey, used from 2018 to 2019, are available in the supplemental materials.

Surveys were exported from Qualtrics to Excel. The surveys included several questions that allowed for open-ended comments, resulting in a total of 301 comments related to motivation for attendance or suggestions for improvements. Based on findings from a literature review and a preliminary review of these comments, two reviewers $(\mathrm{BM}$ and $\mathrm{JH}$ ) identified 34 themes, which were used to code comments. An Excel spreadsheet was used to sort and code the comments thematically. The reviewers divided the comments evenly and coded them independently. To support intercoder reliability, standards for coding were discussed, a few sample comments were coded, and the results compared and discussed. Comments were coded with multiple themes, if relevant, which generated 1,595 coded elements. The coded dataset is available in the supplemental materials.

These 34 themes were then grouped into larger categories, based on findings articulated by Tomaszewski, who found that librarian "conference attendance is used for professional development such as knowledge exchange, peer-to-peer communication, and technology updates," and Vega, whose survey of library workers found the most valuable aspects of conference attendance was "professional rejuvenation and networking." ${ }^{24}$ These categories were the following: 1) Knowledge Exchange; 2) Peer-to-Peer Communication; 3) Networking; 4) Technology Updates; 5) Conference Organization; and 6) Skills Training and Workshops.

In addition to the manual coding and categorization of comments, an analysis of the 1,595 coded elements was conducted using Principal Component Analysis (PCA) in the statistical program SPSS. PCA is a dimension-reduction procedure that was used to condense the 34 subthemes into a smaller, more concise set of overarching themes by identifying correlations among the subthemes. ${ }^{25}$

Likert measures related to the assessment of course outcomes were exported to the statistical programming language $\mathrm{R}$, where visualizations were created. 


\section{Survey Instruments and Overview}

The postconference surveys from 2015, 2016, and 2017 consisted of the following:

1. Three questions to determine how well the three conference learning objectives were met.

2. Three questions to determine the appropriateness of camp pacing and organization.

3. Four questions to measure how well attendees understood the camp's STEM themes.

4. Thirteen questions that measured attendee's enjoyment of meals, sessions, and the overall camp experience.

5. Nine questions that measured the appropriateness of meals, parking, facilities, and cost.

6. One question that measured if the boot camp should recur, and if so, how frequently.

During these formative years, survey questions focused on collecting information that would inform the planning, organization, and pacing of future boot camps, in addition to collecting information that measured if participants felt the camp achieved its learning objectives.

The 2018 and 2019 surveys consisted of the following three sections:

1. Tell us about yourself. A four-question section that measured years worked in libraries, types of libraries worked in, geographic region, and professional organization membership.

2. Tell us about your boot camp attendance. A three-question section that measured previous GLSBCs attended, if similar events had been attended, and what similar events had been attended.

3. Tell us about what you've gained from attending GLSBC. An eight-question section that measured how respondents gained knowledge from the current state of research, how GLSBC met its learning objectives, how GLSBC supported professional development, improvements, and how participants planned to use what they learned at the camp.

As the camp became more established in 2018 and 2019, survey questions shifted to collect information about the demographics of the librarians attending, returning attendees, and participant motivation for camp attendance. Survey questions also shifted from collecting information about whether the camp's learning objectives were being met to how much participants felt they learned.

Survey response rates were 78 percent in 2015, 70 percent in 2016, 62 percent in 2017, 95 percent in 2018, and 70 percent in 2019.

\begin{tabular}{|l|c|c|c|}
\hline \multicolumn{5}{|c|}{ TABLE 1 } \\
\hline Conference Year & Number Registered & Number of Surveys Returned & Response Rate \\
\hline 2015 & 41 & 32 & $78 \%$ \\
\hline 2016 & 66 & 46 & $70 \%$ \\
\hline 2017 & 65 & 40 & $62 \%$ \\
\hline 2018 & 64 & 61 & $95 \%$ \\
\hline 2019 & 57 & 40 & $70 \%$ \\
\hline
\end{tabular}

\section{Results}

Our data analysis took a two-fold approach. First, we analyzed Likert measures related to the achievement of the conference learning objectives. Because the survey was modified in 2018 , these responses were divided into two categories, one category for survey results from 
the 2015-2017 camps and another for results from the 2018 and 2019 camps. Second, we analyzed free-text survey comments from 2015-2019 survey responses to determine participant motivation for conference attendance.

\section{Do GLSBCs Meet Their Learning Objectives?}

Learning Objective 1. Participants will gain detailed knowledge of the current state of scientific and biomedical research, including new terminologies and methodologies.

GLSBC attendees reported that the conference helped them become more familiar with specific areas of scientific research. Table 2 illustrates that, in 2015, 2016, and 2017, more than 90 percent of attendees agreed or strongly agreed that the camp met this learning objective.

\section{TABLE 2}

GLSBC Attendees Gained Detailed Knowledge of the Current State of Scientific Research

\begin{tabular}{|l|c|c|c|c|c|}
\hline & Strongly Agree & Agree & Neither Disagree nor Agree & Disagree & Strongly Disagree \\
\hline 2015 & $46.88 \%$ & $46.88 \%$ & $3.13 \%$ & $3.13 \%$ & 0 \\
\hline 2016 & $56.52 \%$ & $41.3 \%$ & $2.17 \%$ & 0 & 0 \\
\hline 2017 & $47.5 \%$ & $50 \%$ & 0 & 0 & $2.5 \%$ \\
\hline
\end{tabular}

In 2018 and 2019, when asked how much they were able to improve their ability to gain knowledge of the current state of research after attending GLSBC, at least 80 percent of respondents reported that they were able to improve their ability by a moderate amount or more-see table 3 for a breakdown of responses.

\section{TABLE 3}

Most GLSBC Attendees Improved Their Ability to Gain Knowledge of the Current State of Scientific Research by a Moderate Amount or More

\begin{tabular}{|l|c|c|c|c|c|}
\hline & A Great Deal & A Lot & A Moderate Amount & A Little & None At All \\
\hline 2018 & $9.26 \%$ & $38.89 \%$ & $44.44 \%$ & $5.56 \%$ & $1.85 \%$ \\
\hline 2019 & $12.82 \%$ & $23.08 \%$ & $48.72 \%$ & $15.38 \%$ & 0 \\
\hline
\end{tabular}

Learning Objective 2. Participants will develop strategies to enhance their support of scientific research at their home institutions.

GLSBC attendees reported that the conference inspired them to provide new or improved research support services to researchers at their home institution. Table 4 illustrates that, in 2015,2016 , and 2017, at least 80 percent of attendees agreed or strongly agreed that the camp met this learning objective.

TABLE 4
\begin{tabular}{|l|c|c|c|c|c|}
\hline \multicolumn{7}{|c|}{$\begin{array}{l}\text { GLSBC Attendees Are Inspired to Provide New or Improved Research Services at Their } \\
\text { Home Institutions }\end{array}$} \\
\hline & Agree & Strongly Agree & Neither Disagree nor Agree & Disagree & Strongly Disagree \\
\hline 2015 & $31.25 \%$ & $50 \%$ & $12.5 \%$ & $6.25 \%$ & 0 \\
\hline 2016 & $26.83 \%$ & $56.1 \%$ & $17.07 \%$ & 0 & 0 \\
\hline 2017 & $7.5 \%$ & $72.5 \%$ & $17.5 \%$ & $2.5 \%$ & 0 \\
\hline
\end{tabular}


In 2018 and 2019, when asked how much they were able to improve their ability to develop strategies to enhance their support of STEM research at their home institution after attending GLSBC, more than 80 percent of respondents reported that they were able to improve their ability by a moderate amount or more-see table 5 for a breakdown of responses.

\begin{tabular}{|c|c|c|c|c|c|}
\hline Most & BC Attende & $\begin{array}{l}\text { nprovec } \\
\text { istitutio }\end{array}$ & $\begin{array}{l}\text { TABLE } 5 \\
\text { eir Ability to Enhanc } \\
\text { y a Moderate Amour }\end{array}$ & $\begin{array}{l}\text { arch Su } \\
\text { lore }\end{array}$ & their Home \\
\hline & A Great Deal & A Lot & A Moderate Amount & A Little & None At All \\
\hline 2018 & $9.62 \%$ & $32.69 \%$ & $44.23 \%$ & $7.69 \%$ & $5.77 \%$ \\
\hline 2019 & $7.69 \%$ & $28.21 \%$ & $46.15 \%$ & $17.95 \%$ & 0 \\
\hline
\end{tabular}

Learning Objective 3. Participants will identify opportunities for librarian engagement.

GLSBC attendees reported that the conference was a great way to meet or reconnect with other librarians and library service providers in the Great Lakes region. Table 6 illustrates that, in 2015, 2016, and 2017, at least 90 percent of attendees agreed or strongly agreed that the camp achieved this objective.

\section{TABLE 6}

GLSBC Provides an Opportunity for STEM Librarians to Meet and Reconnect

\begin{tabular}{|l|c|c|c|c|c|}
\hline & Strongly Agree & Agree & Neither Disagree nor Agree & Disagree & Strongly Disagree \\
\hline 2015 & $75 \%$ & $25 \%$ & 0 & 0 & 0 \\
\hline 2016 & $67.39 \%$ & $26.09 \%$ & $6.52 \%$ & 0 & 0 \\
\hline 2017 & $72.5 \%$ & $25 \%$ & 0 & 0 & $2.5 \%$ \\
\hline
\end{tabular}

In 2018 and 2019, when asked how much they were able to improve their ability to identify opportunities for librarian engagement after attending GLSBC, at least 80 percent of respondents reported that they were able to improve their ability by a moderate amount or more-see table 7 for a breakdown of responses.

\begin{tabular}{|c|c|c|c|c|c|}
\hline GLS & Ittendees It & $\begin{array}{l}\text { ved the } \\
\text { by }\end{array}$ & $\begin{array}{l}\text { TABLE } 7 \\
\text { ility to Identify Libra } \\
\text { derate Amount or } \mathrm{N}\end{array}$ & Igager & portunities \\
\hline & A Great Deal & A Lot & A Moderate Amount & A Little & None At All \\
\hline 2018 & $12.96 \%$ & $31.48 \%$ & $38.89 \%$ & $14.81 \%$ & $1.85 \%$ \\
\hline 2019 & $7.69 \%$ & $35.9 \%$ & $51.28 \%$ & $2.56 \%$ & $2.56 \%$ \\
\hline
\end{tabular}

\section{GLSBC Attendees Report Motivational Factors}

A total of 301 text comments were gathered across all survey years (2015-2019). These were manually coded and thematically sorted to allow a single comment to be counted across multiple themes, resulting in 1,595 coded elements. As illustrated in figure 1, the most valuable aspect of conference attendance was Knowledge Exchange, a theme present in 725/1595 (45.5\%) of coded elements. This was followed by Peer-to-Peer Communication (501/1595, or $31.4 \%)$, Networking (183/1595, or $11.5 \%)$, Conference Organization $(71 / 1595$, or $4.5 \%)$, Technology Updates (69/1595, or 4.3\%), and Skills Training and Workshops (46/1595, or 2.9\%). 


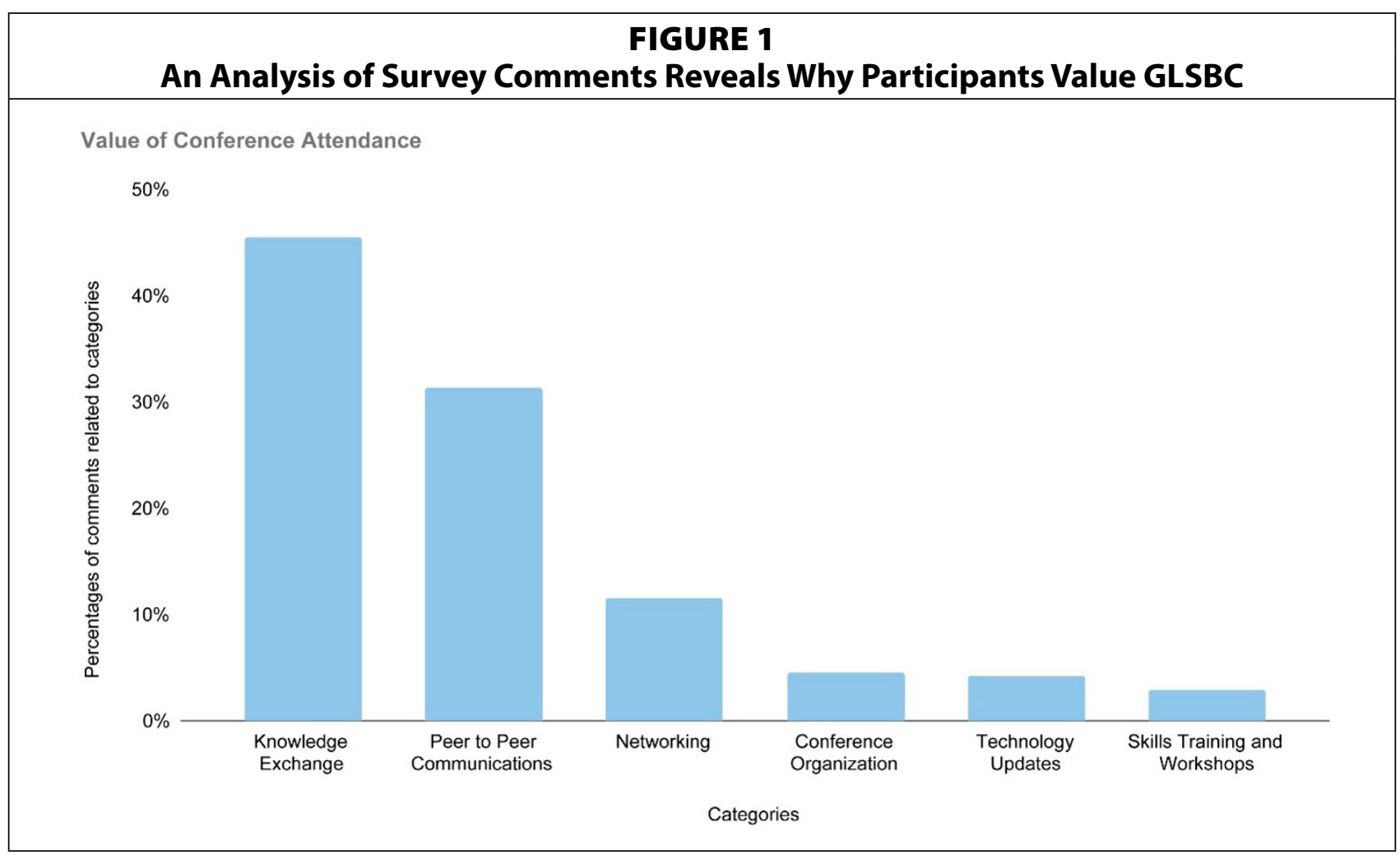

Within the category of Knowledge Exchange, attendees' comments were overwhelmingly related to the value of hearing from science researchers and about scientific research, with 95 percent of comments in the category of Knowledge Exchange related to these themes. Of those, comments related to exposure to science research, insights from scientists, and learning about the state of the field were the most reported. Other popular comments related to the value of exposure to science faculty, exposure to new science developments, opportunities to meet science faculty and ask about their research and library needs, the generation of ideas for resources to include on websites and LibGuides, the dissemination of information to use in outreach, and the dissemination of information to use in teaching. One attendee noted that, as a result of their attendance: "I simply have more confidence in talking to faculty at my institution who specialize in the hard sciences."

Peer-to-Peer Communication was another popular category in the comments, especially opportunities for communicating with other STEM librarians. Within that theme, both informal conversations and more formal experiences, such as lightning talk presentations, motivated boot camp attendance. Popular comments were related to the value of learning from the experiences of other STEM librarians and increased awareness of science-related programming created by other librarians. The remaining common themes centered around understanding the challenges of other science librarians and receiving support from regional STEM librarians. As one noted, "It's an opportunity to meet other librarians in the region and discuss what we are doing, what our institutions are doing and how we could work together." Some attendees noted that outside of the boot camp they had limited opportunities to talk to other science librarians and that having a chance to learn from other STEM librarians was highly valued.

One attendee wrote: "Working at a small, rural institution, the chance to hear how other librarians are supporting their institutions in various ways was one of the most interesting aspects of the conference." 


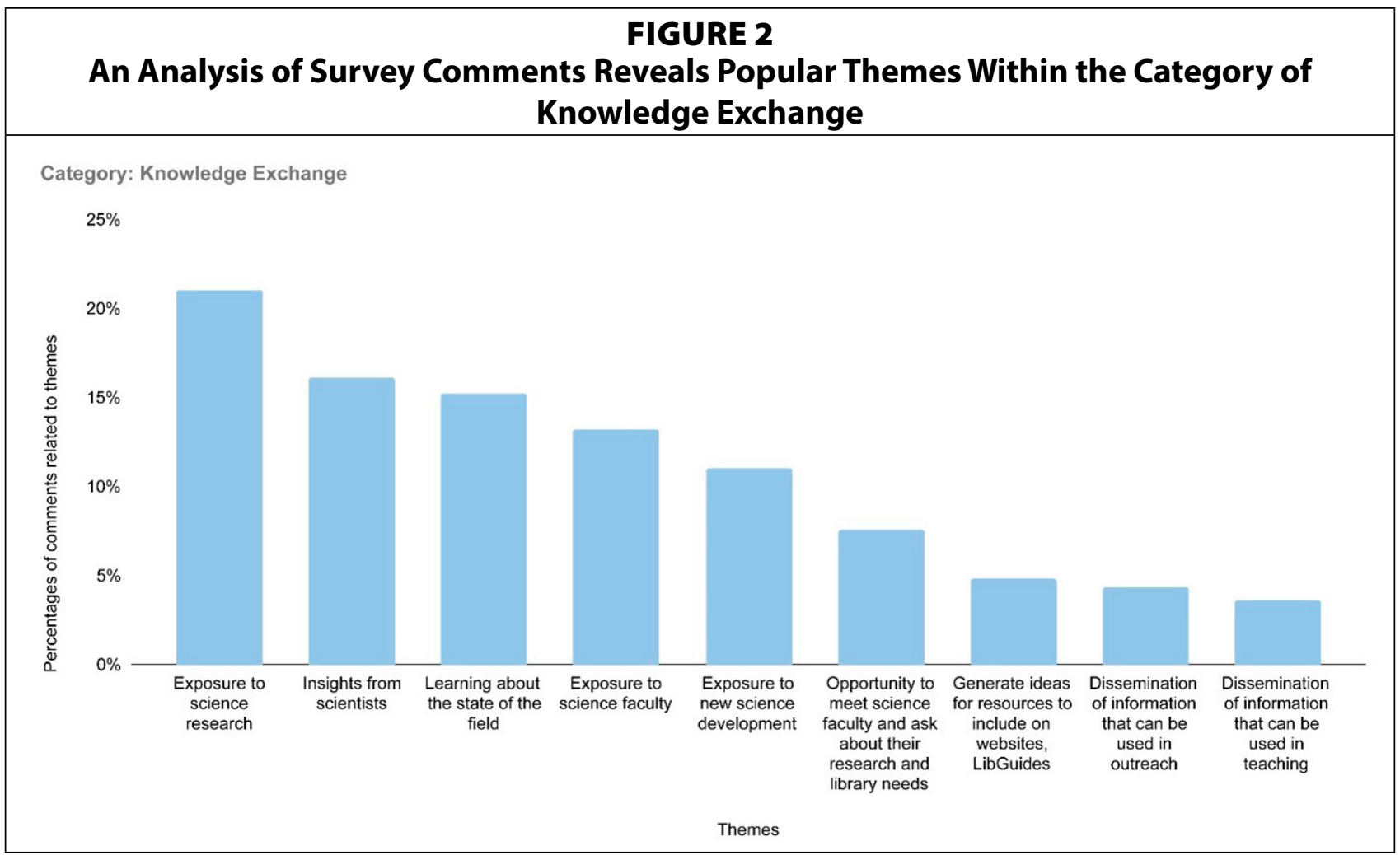

Additional less popular themes in this category were: Useful to have representation from science vendors, Collection development, and Desire for a vendor session.

Networking and socializing with other librarians was another commonly commented upon aspect of the conference. Attendees found socializing with STEM librarians - mingling with others in the field, opportunities for networking with new and experienced librarians, and enjoyable social outings - to be especially valuable. One attendee commented: "There are only two science librarians at my university. It is refreshing to hang with and network with like-minded librarians."

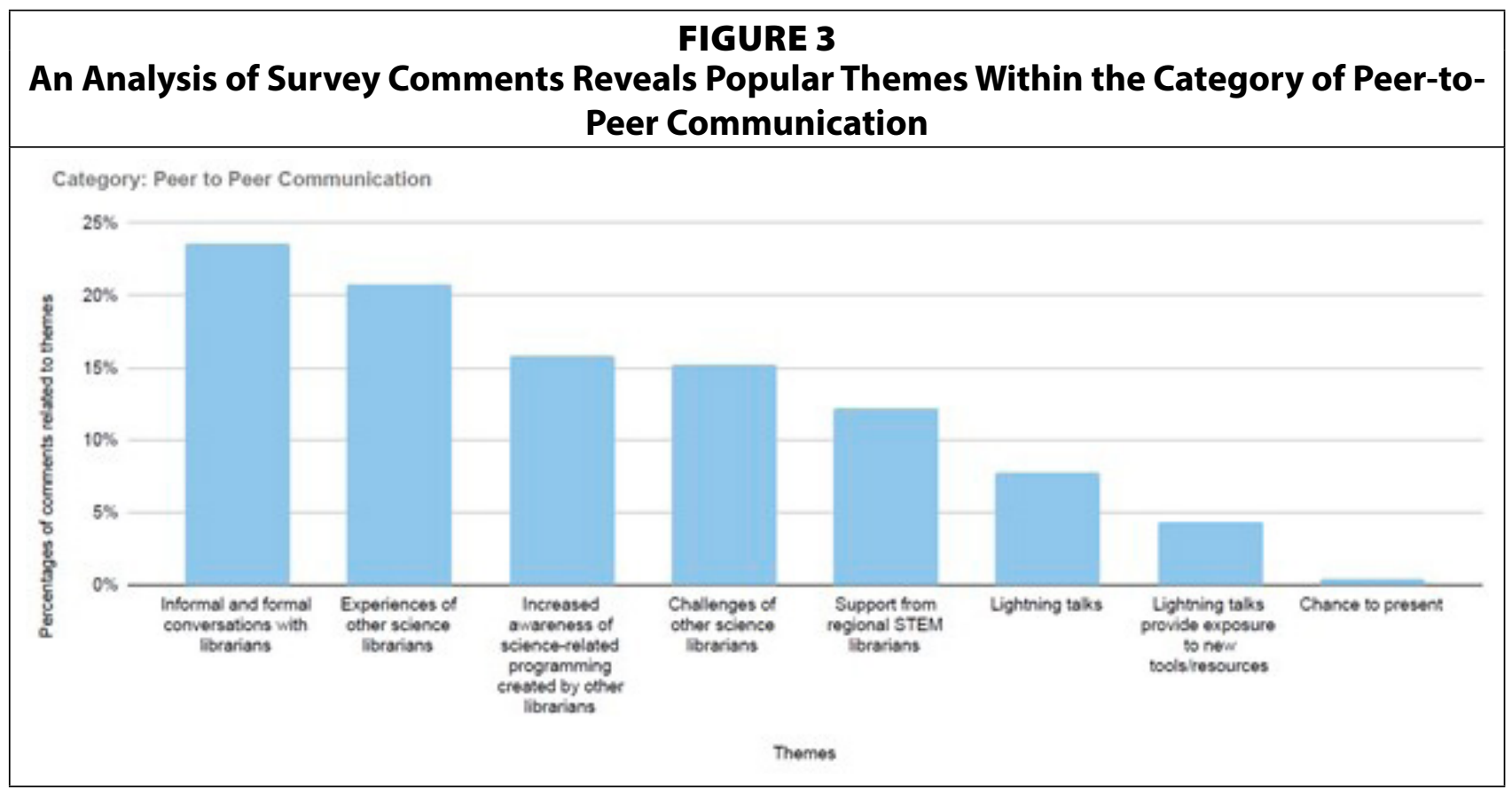


Participants also appreciated the social aspects of the conference including shared meals, breaks, and social outings. And the size of the conference was frequently referenced as being conducive to networking. As one participant wrote: "The whole conference has a very open, collegial, friendly feel, and is a very manageable size."

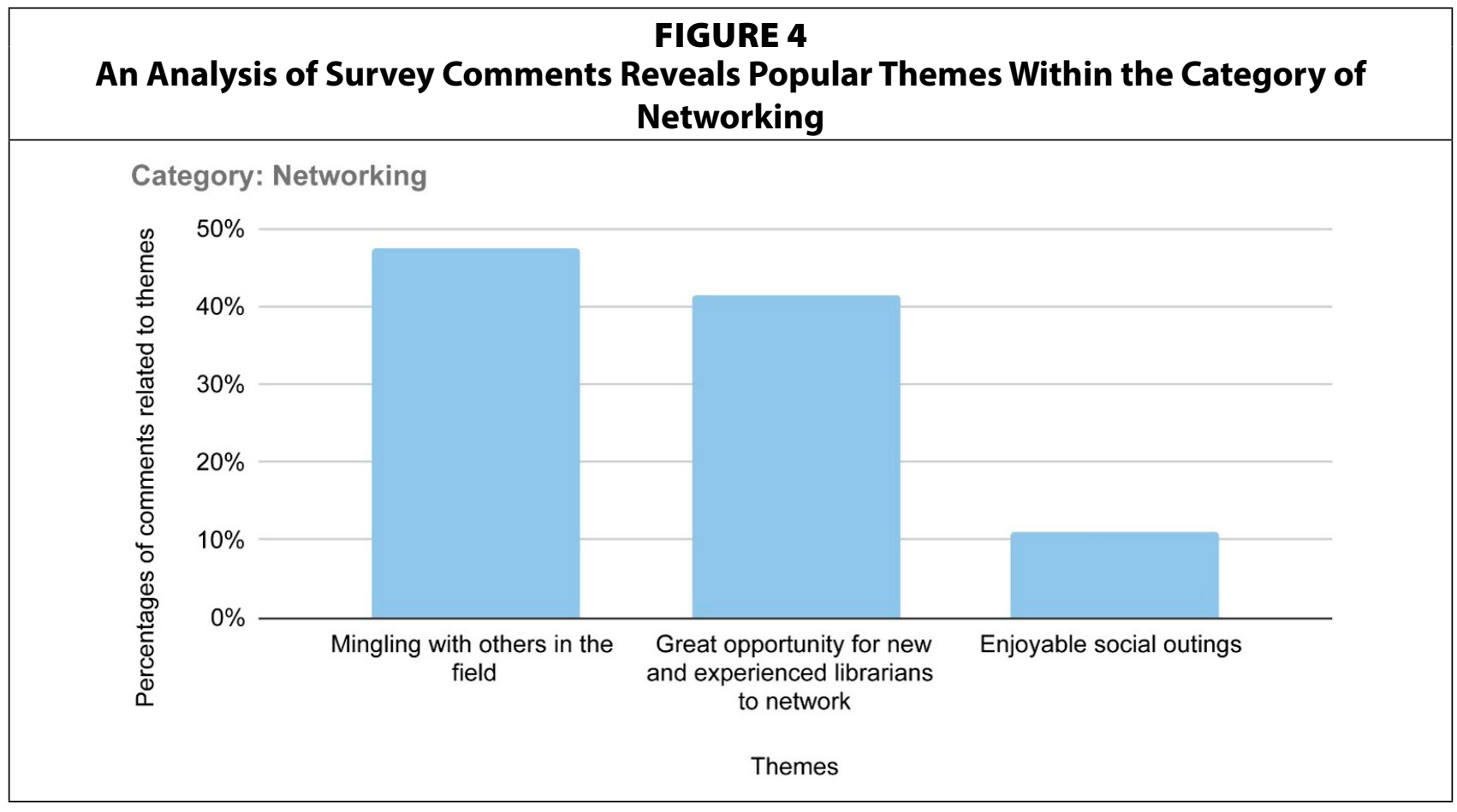

Conference Organization-including cost, accommodations, scheduled activities, and pacing - was noted in 71 comments, and most comments about it were positive. Venues with free and accessible parking, comfortable accommodations, and a range of meal options were rated most favorably. Participants appreciated (coffee) breaks between sessions and social events like lab tours and field trips. Some participants felt the boot-camp schedule should be more relaxed, that it would be valuable to have more social downtime, and that speakers should be required to use microphones. Comments highlighted an appreciation for the camp's affordability. One participant said: "I' $m$ so thrilled to have found this opportunity at such an affordable cost!" and another noted, "It allows those who don't have a big travel budget to get some professional development."

Of lesser interest, but still commented upon, were Technology Updates and Skills, Training, and Workshops. Within those two categories, attendees found the most value in the dissemination of learning tools and resources. Participants also appreciated the options for preconference workshops and hands-on demonstrations during conference presentations. Many comments noted a preference for more workshops and training than those that were offered.

The Skills, Training, and Workshops themes identified were: useful workshops and events, workshops and preconferences provide exposure to new tools, workshops and preconferences provide an opportunity to practice new tools, skills workshops, add webinars outside of the in-person meeting, and committee engagement and project management experience. 


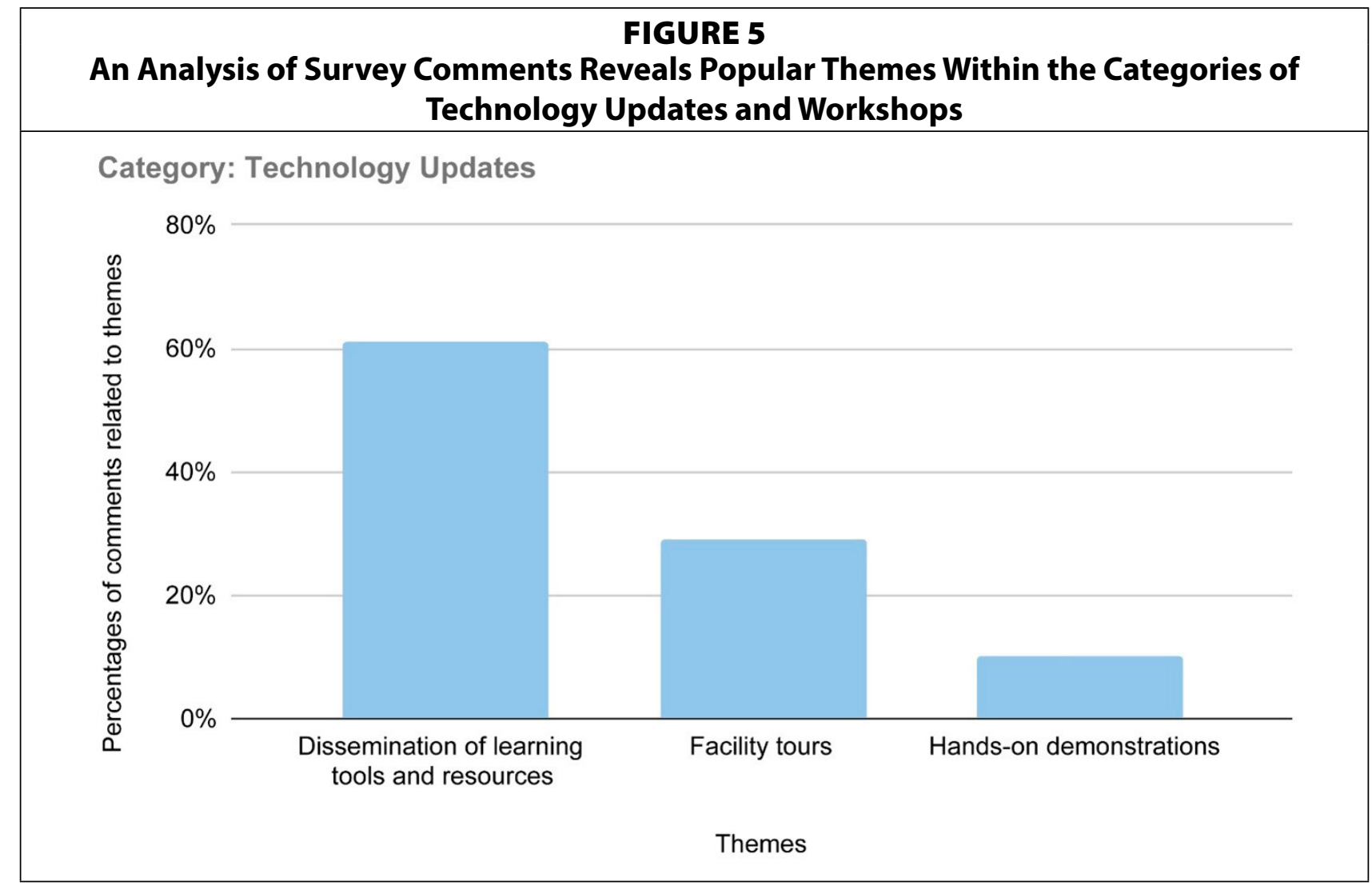

\section{Results of the Principal Component Analysis (PCA) Validate Manual Categorizations}

An assessment expert $(\mathrm{KH})$ was consulted to test the validity of the themes identified through the manual coding of free-text survey comments, using Principal Component Analysis (PCA) in the statistical tool SPSS. PCA is a form of factor analysis (FA) that allows multiple observed variables to be linked with one or more latent, or unobserved, variables called factors. ${ }^{26} \mathrm{FA}$ uses correlations among the observed variables (like subthemes) to estimate factor loadings, which can then be interpreted as the correlation between the observed variables and the factor (example: theme).

Preliminary analyses supported a factor structure appropriate for PCA testing (see figure 6). The Bartlett's test was significant at $p<.001$, and the Kaiser-MeyerOlkin Measure was close to 1.00 $(=0.784)$. A significant Bartlett's test suggests at least some nonzero correlations in the data, and

\begin{tabular}{|c|c|c|}
\hline $\begin{array}{r}\text { PCA of GLSBC Tex } \\
\text { Factorability o } \\
\end{array}$ & $\begin{array}{l}\text { GURE } 6 \\
\text { Responses: Measure } \\
\text { he Correlation Matr }\end{array}$ & \\
\hline KMO and Bartlett's Test & & \\
\hline Kaiser-Meyer-Olkin Measur & of Sampling Adequacy & .784 \\
\hline Bartlett's Test of Sphericity & Approx. Chi-Square & 5175.850 \\
\hline & df & 561 \\
\hline & Sig. & .000 \\
\hline
\end{tabular}
$\mathrm{KMO}$ values $\geq 0.60$ are generally considered factorable. ${ }^{27}$

To create the dimension-reduction dataset, participant comments $(\mathrm{N}=301)$ were manually cross-tabbed with the 34 subthemes identified by the researchers as existing in the data. PCA was then conducted to condense these subthemes into a smaller set of overarching themes. In PCA, 
components represent categories. PCA looks for correlations in the data to determine which variables (for example, subthemes) belong in which component, or category (such as theme), based on how similar to each other those variables (like subthemes) appear to be. PCA does not define or label those themes, however, as the onus is on the researcher to make those distinctions later.

In the present analysis, these correlations, called factor loadings, were used to assign each subtheme (ST1-ST34) to a category in which all other subthemes assigned seemed to have similar content. Through this process, the 34 subthemes were consolidated into just six primary themes.

Early results of the PCA suggested 10 components, or themes, as demonstrated by a scree plot, Eigenvalues, and an initial Pattern Matrix. The results of these tests are available in the supplemental materials. Only two subthemes loaded on the fifth, sixth, and seventh components, and just one subtheme on the ninth and tenth components. Because convention recommends that at least three items load onto a component, it was initially determined that five themes were most likely. ${ }^{28}$

PCA analysis, as with any dimension-reduction procedure, is to be considered second to theory. Thus, a careful review of the subthemes and their respective component affiliations was done to ensure logical placement. As a result, some loadings (subthemes) were relocated to other components (themes) having more homogeneous subthemes. This resulted in a final total of six overarching themes, identified in table 8 as Components 1, 2, 3, 4, 5, and 8 .

The substance of these six components suggested overall themes related to networking, workshops, content, peers, resources, and conference organization. This interpretation supported the findings of the initial categorization of themes, conducted via the manual process described earlier in this paper.

\begin{tabular}{|c|c|c|c|c|c|c|c|c|c|c|}
\hline \multicolumn{11}{|c|}{$\begin{array}{c}\text { TABLE } 8 \\
\text { PCA of GLSBC Text Responses: Final Placement of Rotated Factor Loadings }\end{array}$} \\
\hline & \multicolumn{10}{|c|}{ Pattern Matrix* } \\
\hline & \multicolumn{10}{|c|}{ Component } \\
\hline & 1 & 2 & 3 & 4 & 5 & 6 & 7 & 8 & 9 & 10 \\
\hline ST1 & & & & & -0.722 & & & & & \\
\hline ST2 & & & & 0.541 & & & & & & \\
\hline ST3 & & & & & & & & 0.394 & & \\
\hline ST4 & & & -0.951 & & & & & & & \\
\hline ST5 & & & & & & & & 0.962 & & \\
\hline ST6 & & & & & & & & 0.861 & & \\
\hline ST7 & & & & & 0.861 & & & & & \\
\hline ST8 & & & & & & & & 0.470 & & \\
\hline ST9 & & & & 0.653 & & & & & & \\
\hline ST10 & & & 0.748 & & & & & & & \\
\hline ST11 & & & 0.847 & & & & & & & \\
\hline ST12 & & & 0.847 & & & & & & & \\
\hline ST13 & & & & & & & & 0.452 & & \\
\hline ST14 & & & & & 0.833 & & & & & \\
\hline ST15 & & & & & & & & 0.346 & & \\
\hline
\end{tabular}




\begin{tabular}{|l|c|c|c|c|c|c|c|c|c|}
\hline \multicolumn{7}{|c|}{ TABLE 8 } \\
\hline \\
\cline { 2 - 11 }
\end{tabular}

A table showing the complete list of subthemes, their factor loadings, and their initial and final component placements can be found in the supplemental materials.

\section{Discussion}

Specialized regional conferences meet a professional development need among subject librarians. Clear and measurable learning objectives address two of the aforementioned barriers to conference attendance as a professional development opportunity-difficulty measuring learning gains and difficulty measuring the value of professional development when applied to the job-and make it possible to quantify the value of regional conference attendance as a means of fostering librarian professional development.

Our findings suggest that specialized regional conferences, like the Great Lakes Science Boot Camp for Librarians and Library School Students, improve librarians' ability to identify opportunities for engagement, their ability to develop strategies to enhance support of disciplinary research at their home institutions, and their ability to gain detailed knowledge of the current state of disciplinary research. In 2017 and 2018, when asked to write about how they planned to apply what they learned at the conference to work at their home institu- 
tions, GLSBC attendees included being inspired to offer new services and using ideas or tools learned at the camp to connect with faculty at their home institution as popular responses. The impact of such applications could be measured by librarians and library administrators seeking to quantify conference learning gains or seeking to measure the job applicability of conference attendance.

In 2015, 2016, and 2017, most GLSBC attendees agreed or strongly agreed that the camp helped them become more familiar with specific areas of scientific research. The 2018 and 2019 survey results suggest that a majority of participants felt a moderate amount to a lot of improvement in their ability to gain knowledge of the current state of research.

In 2015, 2016, and 2017, most camp attendees agreed that the camp inspired them to provide new or improved research support services to researchers at their home institution. The 2018 and 2019 survey results suggest that a majority of participants felt a moderate amount to a lot of improvement in their ability to develop strategies to enhance their support of STEM research at their home institution.

In 2015, 2016, and 2017, most camp attendees strongly agreed that the camp offered a means to meet or reconnect with other STEM librarians and library service providers in the Great Lakes Region. The results of the 2018 and 2019 surveys suggest that a majority of participants felt a moderate amount to a lot of improvement in their ability to identify opportunities for librarian engagement.

A total of 301 attendee comments across all survey years (2015-2019) were analyzed to determine factors influencing participant motivation for conference attendance. These factors were then manually coded and thematically sorted to allow a single comment to be counted across multiple themes, resulting in 1,595 coded elements. Through this process, 34 subthemes were identified and grouped into six larger themes: 1) Knowledge Exchange; 2) Peer-to-Peer Communication; 3) Networking; 4) Technology Updates; 5) Conference Organization; and 6) Skills Training and Workshops. Principal Component Analysis (PCA) also was conducted to validate the results of the manual coding process. Initial analyses found the Kaiser-Meyer-Olkin Measure of Sampling Adequacy (KMO) to be 0.784 and the Bartlett's Test of Sphericity to be statistically significant at $p<.001$, indicating that the 1,595 coded elements were suitable for factor analysis. Using PCA, the 34 subthemes were consolidated into a smaller group of overarching themes based on similarities between the subthemes, the results of which supported the manual coding findings. The PCA ultimately resulted in the identification of six components, or themes: 1) networking; 2) workshops; 3) content; 4) peers; 5) resources; and 6) conference organization.

The results of the manual coding of survey comments, reinforced by the statistical analysis findings, suggest that attendees of specialized regional conferences are motivated by opportunities that support knowledge exchange, peer-to-peer communication, and networking; that increase their awareness of technology trends and updates; and that offer opportunities for skill training and workshop attendance. Conference organization, including conference affordability and accessibility, also influences participant motivation for attendance. Out of the 71 comments on the topic of conference organization, 10/71 (14\%) comments remarked positively on the affordability, convenience, length, and timing of the conference. GLSBC attendees are also most likely to drive to the event and to take advantage of the parking, dining, housing options included with registration.

Specialized regional conferences that follow models similar to that of the GLSBC allow subject librarians the opportunity both to hear from researchers in the fields they are sup- 
porting and to communicate and network with other subject librarians. The most common themes in comments from GLSBC attendees were on the value of knowledge exchange, with 45.5 percent of coded elements, followed by Peer-to-Peer Communication and Networking, which together comprised 42.9 percent of elements. The dominance of these themes emphasizes the value that the conference's specialized focus had for attendees. Survey respondents frequently commented that the conference offered a unique opportunity to interact with other STEM librarians, and 26 of the 301 comments noted that the boot camp allowed them to make new connections with STEM librarians, including other librarians in the Great Lakes region.

Limitations of this study are that asking participants to measure the value of their own learning via Likert measures is inherently biased. Nevertheless, participants overwhelmingly report that attendance at the Great Lakes Science Boot Camp is an effective professional development opportunity. Future steps might include distributing pre- and post-learning assessments and interviewing select attendees, particularly attendees who have attended two or more boot camps. It is also important to note that these findings are based on the experiences of STEM librarians; and, though we believe that the recommendations and findings reported would be useful for audiences of non-STEM librarians, readers should consider the context of this conference when assessing its transferability. The Great Lakes Science Boot Camp is one of many regional, specialized professional development opportunities for librarians. Future research directions could also include collaborating with organizers of other specialized regional conferences for librarians to determine if the findings presented in this paper hold true for conferences in other regions or other disciplines.

\section{Conclusion}

The findings of this study suggest that specialized regional conferences like the Great Lakes Sciences Boot Camp for Librarians and Library School Students improve librarian ability to gain knowledge of the current state of research; help librarians identify opportunities for engagement; and help librarians develop strategies to enhance research support at their home institutions. Clearly defined conference learning objectives make it possible to establish measures that librarians and library administrators can use to define pre- and post-conference goals that can help quantify the value of conference attendance. An analysis of GLSBC attendee survey comments reveals six themes that motivate conference attendance: 1) Knowledge Exchange; 2) Peer-to-Peer Communication; 3) Networking; 4) Technology Updates; 5) Conference Organization; and 6) Skills Training and Workshops.

\section{Acknowledgments}

The authors would like to thank the Great Lakes Science Boot Camps for Librarians organizers for collecting and sharing the data that made this study possible: Katherine Akers and Randy Dykhuis (Wayne State University, 2015); Thurston Miller (University of Notre Dame, 2016); Eric Tans (Michigan State University, 2017); Sarah Huber and Bethany McGowan (Purdue University, 2018); and Jennifer Hart and Cecilia Smith (University of Chicago, 2019). We would also like to thank all members of GLSBC organizing committees (2015-2019) for their work planning successful events.

\section{Funding Declaration}

The development of some of the trainings reported in this study were supported by the National Network of Libraries of Medicine (NNLM) Greater Midwest Region (GMR), National Library 
of Medicine (NLM), and National Institutes of Health (NIH) under cooperative agreement number 1UG4LM012346. This content is solely the responsibility of the authors and does not necessarily represent the official views of the National Institutes of Health.

\section{Data Availability Statement}

The raw data, coded data, and supplemental materials for this study are available for download in Purdue e-Pubs, available at: https://docs.lib.purdue.edu/cgi/preview.cgi? article=1008\&context=lib_ fssup

\section{Notes}

1. Sally A. Gore, "Shaping Up: Boot Camp and Other Programs Addressing Professional Development Needs of Science Librarians," Medical Reference Services Quarterly 30, no. 2 (2011): 130-40.

2. Bethany S. McGowan, "2018 Great Lakes Science Boot Camp Schedule and Assessment Survey," Libraries Faculty and Staff Creative Materials (paper 26, 2019), https://docs.lib.purdue.edu/lib_fscm/26.

3. Robert Tomaszewski and Karen I. MacDonald, "Identifying Subject-specific Conferences as Professional Development Opportunities for the Academic Librarian," Journal of Academic Librarianship 35, no. 6 (2009): 583-90.

4. Cynthia Tysick, "Attending Conferences outside of Librarianship," College \& Undergraduate Libraries 9, no. 2 (2002): 75-81; Tomaszewski and MacDonald, "Identifying Subject-specific Conferences as Professional Development Opportunities for the Academic Librarian," 583-90.

5. Crystal L. Renfro and Lori J. Ostapowicz Critz, “How to Be a Subject Specialist When You Aren't: Engineering Librarianship for the Non-engineer" (paper presented at 2018 ASEE Annual Conference \& Exposition, June 23-27, 2018, Salt Lake City, Utah).

6. Tomaszewski and MacDonald, "Identifying Subject-specific Conferences as Professional Development Opportunities for the Academic Librarian," 583-90.

7. Tomaszewski and MacDonald, "Identifying Subject-specific Conferences as Professional Development Opportunities for the Academic Librarian," 583-90.

8. Gore, "Shaping Up," 130-40.

9. Samantha Schmehl Hines, “What Do Library Workers Want from Professional Conferences?" in Revolutionizing the Development of Library and Information Professionals: Planning for the Future (Hershey, PA: IGI Global, 2014), 1-16.

10. Hines, "What Do Library Workers Want From Professional Conferences?".

11. Rachel Harrison, "Unique Benefits of Conference Attendance as a Method of Professional Development for LIS Professionals," Serials Librarian 59, no. 3/4 (2010): 263-70; Fehintola N. Onifade, Clara C. Okoro, and Gifty O. Boakye, "Career Progression of Librarians in Nigeria and Ghana Universities," Information Impact: Journal of Information and Knowledge Management 9, no. 3 (2018): 33-46; P. Sawant and Sarika Sawant, "Professional Development Programmes and Skill Development of Librarians," 8 (2017): 217-21; Karen Venturella and Moddie Breland, "Supporting the Best: Professional Development in Academic Libraries," Journal of New Librarianship 4, no. 1 (2019): 283-92.

12. Hines, "What Do Library Workers Want from Professional Conferences?" 1-16.

13. Kaetrena Davis Kendrick, Deborah Tritt, and Echo Leaver, "Link Up the Sticks: Rural Academic Librarians and Professional Development Opportunities," Codex: Journal of the Louisiana Chapter of the ACRL 2, no. 3 (2013).

14. Hines, "What Do Library Workers Want from Professional Conferences?"

15. Hines, "What Do Library Workers Want from Professional Conferences?"

16. Gore, "Shaping Up," 130-40.

17. Lucy Eleonore Lyons, "The Dilemma for Academic Librarians with Collection Development Responsibilities: A Comparison of the Value of Attending Library Conferences versus Academic Conferences," Journal of Academic Librarianship 33, no. 2 (2007): 180-89.

18. Hines, "What Do Library Workers Want from Professional Conferences?" 1-16.

19. Edward Bilodeau and Pamela Carson, "The Role of Communities of Practice in the Professional Education of Academic Librarians," Education for Information 31, no. 1/2 (2015): 25-51.

20. Robyn L. Houlden and Christine P. Collier, "Learning Outcome Objectives: A Critical Tool in Learnercentered Education," Journal of Continuing Education in the Health Professions 19, no. 4 (1999): 208-13.

21. Amanda Nichols Hess, "Equipping Academic Librarians to Integrate the Framework into Instructional Practices: A Theoretical Application," Journal of Academic Librarianship 41, no. 6 (2015): 771-76. 
22. Joan E. Grusec, "Social Learning Theory and Developmental Psychology: The Legacies of Robert R. Sears and Albert Bandura," Developmental Psychology 28, no. 5 (1994): 776-86, https://doi.org/10.1037/0012-1649.28.5.776.

23. Ramirose I. Attebury, "Professional Development of Academic Librarians: A Phenomenological Study of Meaningful and Transformational Experiences" (PhD diss., University of Idaho, 2016); Hazel Jones and Alexandra Hugman, "Does a Conference Act as a Catalyst for Further Publications and Collaborations? A Pilot Study of a Small Science and Mathematics Education Conference," in Proceedings of The Australian Conference on Science and Mathematics Education (formerly UniServe Science Conference) (2010).

24. Tomaszewski and MacDonald, "Identifying Subject-specific Conferences as Professional Development Opportunities for the Academic Librarian," 583-90; Robert D. Vega and Ruth S. Connell, "Librarians' Attitudes toward Conferences: A Study," College \& Research Libraries 68, no. 6 (2007): 503-16.

25. Ian T. Jolliffe, Principal Component Analysis, 2nd ed. (New York, NY: Springer, 2002).

26. George H. Dunteman, Principal Components Analysis (Thousand Oaks, CA: Sage, 1989).

27. Jolliffe, Principal Component Analysis.

28. J. Edward Jackson, “A User's Guide to Principal Components,” Wiley Online Library (2004). 